\title{
The development and application of remote sensing to monitor sand dune habitats
}

\author{
JM Brownett ${ }^{1,2} \cdot$ RS Mills $^{2}$
}

Received: 23 February 2016 / Revised: 15 February 2017 / Accepted: 9 March 2017 /Published online: 4 July 2017

(C) The Author(s) 2017. This article is an open access publication

\begin{abstract}
Sand dunes are complex systems that contain several habitats, often as mosaics or transitions between types. Several of these habitats are afforded protection under European Legislation and in the UK nationally within Special Areas of Conservation (SAC) and Sites of Special Scientific Interest (SSSI). Natural England has a statutory duty to report to Europe on the conservation status and condition of sand dunes; and is required to report to the UK Government on designated sites. To achieve this we have sought ways of capturing, analysing and interpreting data on the extent and location of sand dune habitats. This requires an ability to be able to obtain data over large areas of coastline in an efficient way. Natural England and Environment Agency Geomatics have worked collaboratively for over 16 years, sharing data and ecological knowledge. In 2012 work started to evaluate the use of remote sensing to map UK BAP and Annex I sand dune habitats. A methodology has now been developed and tested to map sand dune habitats. The key objective was to provide an operational tool that will help to map these habitats and understand change on sites around England. This has been achieved through analysis of LIDAR and Compact Airborne Spectrographic Imager (CASI) data using Object Orientated Image Analysis. Quality Control (QC) and accuracy assessments have shown this approach to be successful and 11 sites
\end{abstract}

JM Brownett

jonathan.brownett@ naturalengland.org.uk

RS Mills

rachael.mills@naturalengland.org.uk

1 Environment Agency, Geomatics, Lower Bristol Road, Bath BA2 9ES, UK

2 Natural England, Foss House, Kings Pool, 1-2 Peasholme Green, York YO1 7PX, UK have been mapped to date. These techniques are providing a new approach to monitoring change in coastal vegetation communities and informing management of protected sites.

Keywords Sand dunes $\cdot$ Remote sensing $\cdot$ Habitat mapping · CASI $\cdot$ Annex 1 habitats $\cdot$ Habitats directive $\cdot$ England Coastal monitoring $\cdot$ Object orientated image analysis . Environmental monitoring · Operational · Collaborative agreement $\cdot \mathrm{SAC} \cdot \mathrm{SSSI}$

\section{Introduction}

The paper is based on a presentation on the use of remote sensing to monitor sand dunes in England given at the Sand Dune Hydro-Ecology Group seminar held in Swansea in September 2013. This presentation summarised the initial project, which was looking at whether remote sensing could be used to map sand dune habitats in a repeatable and effective method, combining the expertise of remote sensing analysts and ecological specialists. This was carried out as a collaborative project between Environment Agency and Natural England. Reported here is an overview of the collaborative project; the operational tool - including data preparation and image classification, and an update on the work that has taken place up to 2016.

This project started in 2012 and is part of a wider programme of collaborative working between Natural England and Environment Agency Geomatics that has taken place over the past 16 years (Petchey et al. 2011). The programme is investigating the operational use of remote sensing as part of environmental monitoring for a range of intertidal and terrestrial habitats. A key benefit of this work has been to show how public bodies (and others) working together to share 
knowledge, data and evidence can achieve significant outcomes and efficiencies.

The programme of work has led to the development of innovative methods for improving the accuracy of habitat mapping through the development of remote sensing techniques for marine Special Areas of Conservation (SAC) monitoring (Brown et al. 2003). Petchey et al. (2011) identified that the operational use of remote sensing data for coastal sand dune habitat monitoring required further development to test whether remote sensing data could be used alongside ecological ground data to produce an accurate visual representation and data on the habitat location and extent on a site. Natural England and Environment Agency have, over the past 4 years, assessed the application of remote sensing to map UK BAP
Priority (JNCC 2015) and Annex I (JNCC 2016) sand dune habitats. Developing a consistent approach and methodology which has been tested on SACs designated for their sand dune habitats, Fig. 1 shows the sites mapped up to 2015.

Remote sensing has been shown to have the potential for the production of habitat maps at various habitat scales to a high accuracy using a variety of input data (Corbane et al. 2015). Pixel based habitat mapping methods, such as the supervised Maximum Likelihood Classification (MLC), have been the traditional method for producing habitat maps (Lucas et al. 2007). The ability and cost of processing large datasets with complex methods have in the past been a limiting factor; however, due to technological developments more complex processing can be undertaken (Toth and Jozkow
Fig. 1 Location map of the Sand Dunes sites mapped by 2015

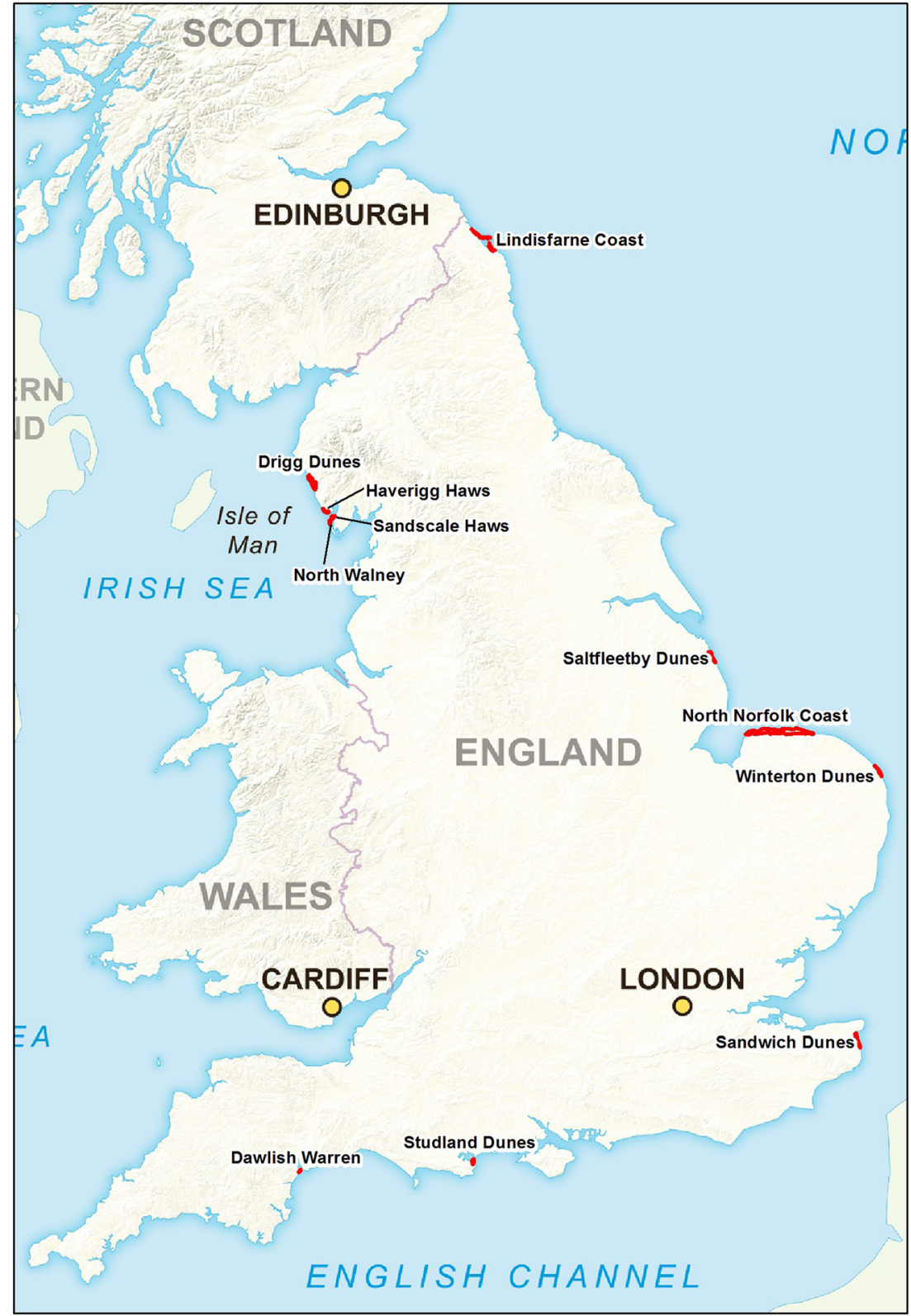


2016), including the processing of image objects instead of pixels. The use of Object Based Image Analysis (OBIA) has been shown to produce higher accuracy results than traditional pixel based methods (Hussain et al. 2013 \& Strasser and Lang 2015). This OBIA method has been used to develop the mapping discussed in this paper, combining the technical expertise from Environment Agency and specialist ecological and site knowledge from Natural England. This has enabled a high confidence in the accuracy of the results to be obtained and an operational method to be developed.

The technique of capturing, analysing, and interpreting remote sensing and ecological data require clear consistent definitions of features on the ground, the classification used corresponds with Annex I habitats (Table 3) (JNCC 2016) of the Habitats Directive (The Conservation of Habitats and Species Regulations 2010 (as amended). Coastal sand dunes are protected under European legislation and their habitats are listed under Annex I of the Habitats Directive (2010 as amended). There is a requirement under Article 17 for Member States to report on implementation of the Habitats Directive every six years (JNCC 2013). This requires UK Agencies to report on the conservation status of individual habitats and species listed under the Annexes of the Directive (e.g. distribution, range and area). As with other dynamic coastal habitats dunes can be difficult to monitor and hence obtain data on changes in extent and quality. The aim of this project was to create new methodologies and techniques to capture this information in a repeatable and consistent way for Natural England to use in European and national reporting and conservation management, including Special Sites of Scientific Interest (SSSI). The Environment Agency value dunes as natural flood defences (Pye et al. 2007), and information on the extent and structure of dunes is of benefit to them.

\section{Methods}

\section{Data collection}

The Sand Dune Survey of Great Britain (Radley 1994) is used as a starting point to identify the location of these coastal sand dune habitats within protected sites. This is then combined with the relevant SSSI boundary to create a survey polygon. The position of mean high water (MHW) has been used to define the seaward limit for the survey and ensures data capture does not lose features such as embryo dunes. This survey polygon is then used by Environment Agency's aerial surveyors to capture two datasets CASI (Compact Airborne Spectrographic Imager) and LIDAR. These datasets are both captured and processed in-house by Environment Agency Geomatics.

\section{CASI}

Multispectral data is captured using an ITRES Compact Airborne Spectrographic Imager (CASI) 1500. This is used to capture spectral data using a 22 channel set up (Table 1) designed for coastal and intertidal work and at a resolution of $1 \mathrm{~m}$. Data capture is targeted in the summer season, with the optimum conditions for vegetation between June - August, although later capture in September is possible provided the vegetation on the target site is not in senescence.

The data is radiometrically corrected using ITRES algorithms following annual spectral calibrations, then Quality Checked (QC) for gaps, lighting anomalies and distortions within each flight line. The data is then orthorectified using LIDAR data and mosaicked into a single dataset. Final QC are then carried out to ensure the flight lines edges have correctly aligned and for lighting differences between the flight lines.

\section{LIDAR}

LIDAR data is captured using an Optech Gemini ALTM, during the winter flying season (October-March). An exception

Table 1 Wavelengths of CASI bands used. Each band shows the Wavelength centre and Spectral width of the band in Nanometres.

\begin{tabular}{|c|c|c|}
\hline CASI Channel Number & $\begin{array}{l}\text { Wavelength } \\
\text { (Centre (Nanometres)) }\end{array}$ & $\begin{array}{l}\text { Spectral Width } \\
\text { (Full Width } \\
\text { Half Maximum) } \\
\text { (Nanometres) }\end{array}$ \\
\hline 001: & 402.2 & $+/-13.0$ \\
\hline 002: & 449.6 & $+/-13.0$ \\
\hline 003: & 494.5 & $+/-13.0$ \\
\hline 004: & 519.3 & $+/-11.8$ \\
\hline 005: & 561.9 & $+/-14.2$ \\
\hline 006: & 583.2 & $+/-7.1$ \\
\hline 007: & 603.3 & $+/-8.3$ \\
\hline 008: & 617.4 & $+/-5.9$ \\
\hline 009: & 630.4 & $+/-7.1$ \\
\hline 010: & 648.2 & $+/-8.3$ \\
\hline 011: & 668.3 & $+/-4.7$ \\
\hline 012: & 680.1 & $+/-7.1$ \\
\hline 013: & 690.7 & $+/-3.5$ \\
\hline 014: & 697.8 & $+/-3.5$ \\
\hline 015: & 707.3 & $+/-3.5$ \\
\hline 016: & 716.7 & $+/-5.9$ \\
\hline 017: & 753.3 & $+/-7.1$ \\
\hline 018: & 804.1 & $+/-13.0$ \\
\hline 019: & 858.5 & $+/-13.0$ \\
\hline 020: & 883.2 & $+/-11.8$ \\
\hline 021: & 962.3 & $+/-8.3$ \\
\hline 022: & 1010.7 & $+/-14.2$ \\
\hline
\end{tabular}


to this is if suitable resolution ( $0.5 \mathrm{~m}$ or $1 \mathrm{~m}$ resolution) archive data is available within the past $0-2$ years and no storm events have occurred causing major site changes. There is potential for some change in dune topography between the LIDAR and CASI data capture. However, the reason for preference of winter LIDAR capture over summer is that the frequency of laser pulses reaching the ground is greater in winter especially through deciduous vegetation. The implications of this are that a more accurate terrain model can be generated, and hence better modelling of vegetation heights.

LIDAR processing goes through a number of stages: including on trajectory quality, flight line overlap and coverage and ground control to verify accuracy. All of these stages must be passed including a Quality Control (QC) to ensure that the elevation Root Mean Square Error is better than $+/-15 \mathrm{~cm}$. The data is then processed to produce a Digital Terrain Model (DTM) using semi-automated raster classification and filtering techniques. Finally a repeat of the ground truthing is carried out alongside a number of other QC procedures to ensure full coverage and absence of striping. The final outputs from this, which are used in the habitat mapping, are Digital Surface Model (DSM) based on First Returns, a DTM and Intensity data. From these products two derived products are made: a slope model from the DTM and Canopy Height Model (CHM) from the DTM and DSM.

A known limitation of winter LIDAR capture is that returns are not from the top of the tree and shrub canopy in deciduous vegetation but rather large branches and the trunk lower in the tree structure. This means that the height of tall vegetation recorded in the CHM, are likely to be under calculating the vegetation height. Knowledge of this limitation has enabled us to develop a methodology which takes this into account.

\section{Ground data collection}

Ground data collection is carried out alongside the aerial data collection to assist with interpretation of imagery (Table 2). It is used to train the classification system and validate the final habitat map. Data is collected as soon as possible after the CASI data capture, normally within 1-2 months. The field collection of data can take between 1 and 4 days. The methodology for collection of ground data is to capture a good spatial spread of samples for each habitat type present on the site. Access on the site and time limitations may lead to multiple samples of different habitats being collected within a small area; however subsequent samples need to be collected over the rest of the site. This is to ensure that variations in habitat across the site are picked up and that spectral differences between flight lines can also be identified in the analysis.

When collecting ground data, a CASI true colour image is taken into the field onto which polygons are drawn to identify the location of habitats and must only contain a single habitat class, according to our habitat classes (Table 3 ). This action is to reduce errors from poor ground data, by mapping the features seen, so greater confidence can be assigned to the quality of data. For each ground data sample collected the following are recorded; class name, prominent species, other notes of interest (i.e. recent management, vegetation heights or topography) and surveyor. For mosaics or transitional habitats present, polygons are drawn and a description of key species is noted, but no class is assigned. Many of the samples are photographed, where possible with GPS co-ordinates to help interpret the final maps and address queries.

To help gain an understanding of the site, plan effective and time efficient site visits, and to get a good spatial spread of samples it is important to work closely with the site officer

Table 2 Data collection dates

\begin{tabular}{llll}
\hline Site name & CASI date & LIDAR date & Ground data collection date \\
\hline Winterton Dunes & July 2012 & March 2011 & September 2012 \\
Studland Dunes & September 2012 & March 2012 & February 2013 \\
Saltfleetby Dunes & July 2012 & March 2012 & April 2013 \\
Seascale and Drigg Coast & June 2013 & March 2012 & September 2013 \\
Eskmeals & June 2013 & March 2012 & September 2013 \\
Haverigg Haws & July 2013 & January 2013 & September 2013 \\
Sandscale Haws & July 2013 & March 2012 & September 2013 \\
North Walney & July 2013 & March 2012 & September 2013 \\
Lindisfarne & July $2013 *$ & November 2012 & October 2013 \\
Dawlish Warren & July 2013 & November 2011 & October 2013 \\
Sandwich Bay & July 2013 & October 2013 & November 2013 \\
North Norfolk Coast & September 2014 & January/ February 2014 & September 2014 \\
Sefton Coast & August 2015 & Planned - Winter 2015 & September 2015 \\
\hline
\end{tabular}

*Data courtesy of the Northeast Regional Coastal Monitoring Programme, copyright Scarborough Borough Council 
Table 3 Habitat Map Classes and equivalent Annex I class where appropriate

\begin{tabular}{|c|c|}
\hline Habitat map class & Annex I \\
\hline \multicolumn{2}{|l|}{ Annuals } \\
\hline \multicolumn{2}{|l|}{ Artificial surface } \\
\hline Bare Sand - beach & 1140 - Mudflats and sandflats not covered by seawater at low tide \\
\hline \multicolumn{2}{|l|}{ Bare sand - within Dune } \\
\hline \multicolumn{2}{|l|}{ Bare soil/ rock } \\
\hline \multicolumn{2}{|l|}{ Broadleaved dune woodland } \\
\hline \multicolumn{2}{|l|}{ Coniferous dune woodland } \\
\hline \multicolumn{2}{|l|}{ Dune scrub } \\
\hline Dune scrub - creeping willow & 2170 - Dunes with Salix repens ssp. argentea (Salicion arenariae) \\
\hline Dune scrub - Sea buckthorn & 2160 - Dunes with Hippophae rhamnoides \\
\hline Dune slack & 2190 - Humid dune slacks \\
\hline Dune slack - Creeping willow & 2170 - Dunes with Salix repens ssp. argentea (Salicion arenariae) \\
\hline Embryo dune & 2110 - Embryonic shifting dunes \\
\hline Fixed dune grassland & 2130 - Fixed dunes with herbaceous vegetation ("grey dunes") \\
\hline Fixed dune heath & 2150 - Atlantic decalcified fixed dunes (Calluno-Ulicetea) \\
\hline \multicolumn{2}{|c|}{ Coastal and floodplain grazing marsh } \\
\hline \multicolumn{2}{|l|}{ Improved grassland } \\
\hline \multicolumn{2}{|l|}{ Invasive } \\
\hline Marram-dominated dune & 2120 - Shifting dunes along the shoreline with Ammophila arenaria ("white dunes") \\
\hline Mud - intertidal & 1140 - Mudflats and sandflats not covered by seawater at low tide \\
\hline \multicolumn{2}{|l|}{ Other broadleaved woodland } \\
\hline \multicolumn{2}{|l|}{ Other coniferous woodland } \\
\hline \multicolumn{2}{|l|}{ Other grassland } \\
\hline \multicolumn{2}{|l|}{ Other intertidal vegetation } \\
\hline \multicolumn{2}{|l|}{ Other scrub } \\
\hline \multicolumn{2}{|l|}{ Permanent water } \\
\hline \multicolumn{2}{|l|}{ Reedbeds } \\
\hline \multicolumn{2}{|l|}{ Saltmarsh } \\
\hline \multicolumn{2}{|l|}{ Shingle - non vegetated } \\
\hline \multicolumn{2}{|l|}{ Shingle - vegetated } \\
\hline Weedy/ruderal vegetation & \\
\hline
\end{tabular}

when planning the site visit. We also aim to have a site officer come out during the visit; this can help clarify unique site features, on-going management and natural changes that are occurring on the site.

The ground data is digitised as polygons into ArcGIS by Natural England, with all the sample information recorded as attributes. The data entry is validated to ensure that classes are correctly identified and to avoid the inconsistency that can arise when multiple surveyors work on a site (Hearn et al. 2011).

\section{Data analysis}

The data analysis process runs through seven key stages to produce the habitat map (Fig. 2). The first stage, data preparation, was undertaken using ArcGIS 9.3 or 10.2 and ERDAS
Imagine 9.3 or 2014 . This includes setting all datasets to the British National Grid projection system in a single software package. These datasets are: CASI, DTM, CHM and Slope. This is done to avoid the classification software thinking there are different project systems being used due to software formatting of the projection system. The null data value is also set for the DTM to the lowest actual elevation value; allowing the graphical functionality to work in the classification software.

Rather than traditional pixel based methods (Lucas et al. 2007), an object based image analysis (OBIA) method is used to undertake the classification. This classification used the OBIA software Trimble eCognition v8.9 or 9.0. OBIA has been shown to give improved results with a higher accuracy compared to pixel based methods (Hussain et al. 2013 \& Strasser and Lang 2015). It also provides a powerful solution 


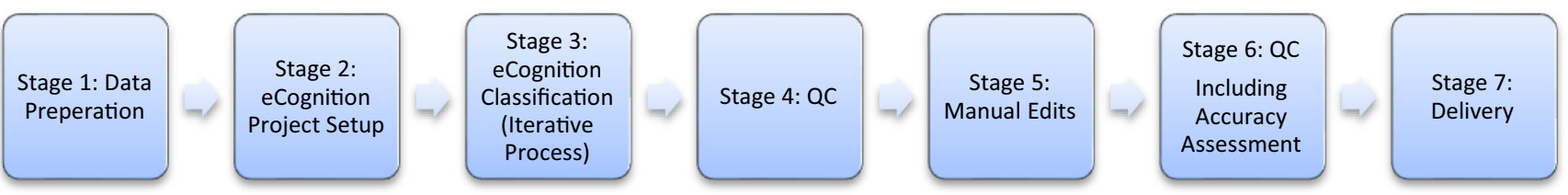

Fig. 2 Habitat Mapping Workflow. This shows the 7 stages in the Habitat Mapping process, ranging from Data Preparation to Delivery. There are two stages covering eCognition, then stages 4, 5 \& 6 which cover the QC and Manual Edits which help to ensure a high quality mapping product

to using various data sources and through technological developments is able to deal with the complex processing needed (Toth and Jozkow 2016). OBIA has been successfully used by large detailed habitat mapping studies, such as the Phase 1 mapping of Wales (Lucas et al. 2011). It is also recommended and used in the Making Earth Observation Work projects, looking to create a Living Map of the UK (Medcalf et al. 2011 \& Medcalf et al. 2013).

Stage 2 (Fig. 2) is the Project Setup in eCognition, this includes loading all the image and thematic data (as Shapefiles) and the process ruleset, this ruleset loads the Process Tree, Class list, and features needed for the classification. The use of eCognition allows a decision tree methodology to be applied (called a Process Tree in eCognition) and orders the various classification stages (Fig. 3). These stages contain a number of algorithms which implement the classification, including: segmentations, classifications and merging.

Initial steps in the classification are to carry out a chessboard segmentation, identification of intertidal areas, exclusion of parts of the image outside the area of interest (AOI) and classification into two classes; Vegetation and NonVegetation (Fig. 3- Part 1). The chessboard segmentation creates square objects with their size equalling the CASI resolution. This is done, to ensure that small subtle features; such as embryo dunes and bare sand within dunes are retained as single objects during the later multi-resolution segmentations, and helps improve the classification accuracy of these features. After the chessboard segmentation is carried out, it is possible to start classifying the objects. The first classification that takes place is to identify the intertidal area, with the
Fig. 3 A workflow outlining the ecognition process tree used in Fig. 2 - Stage 3

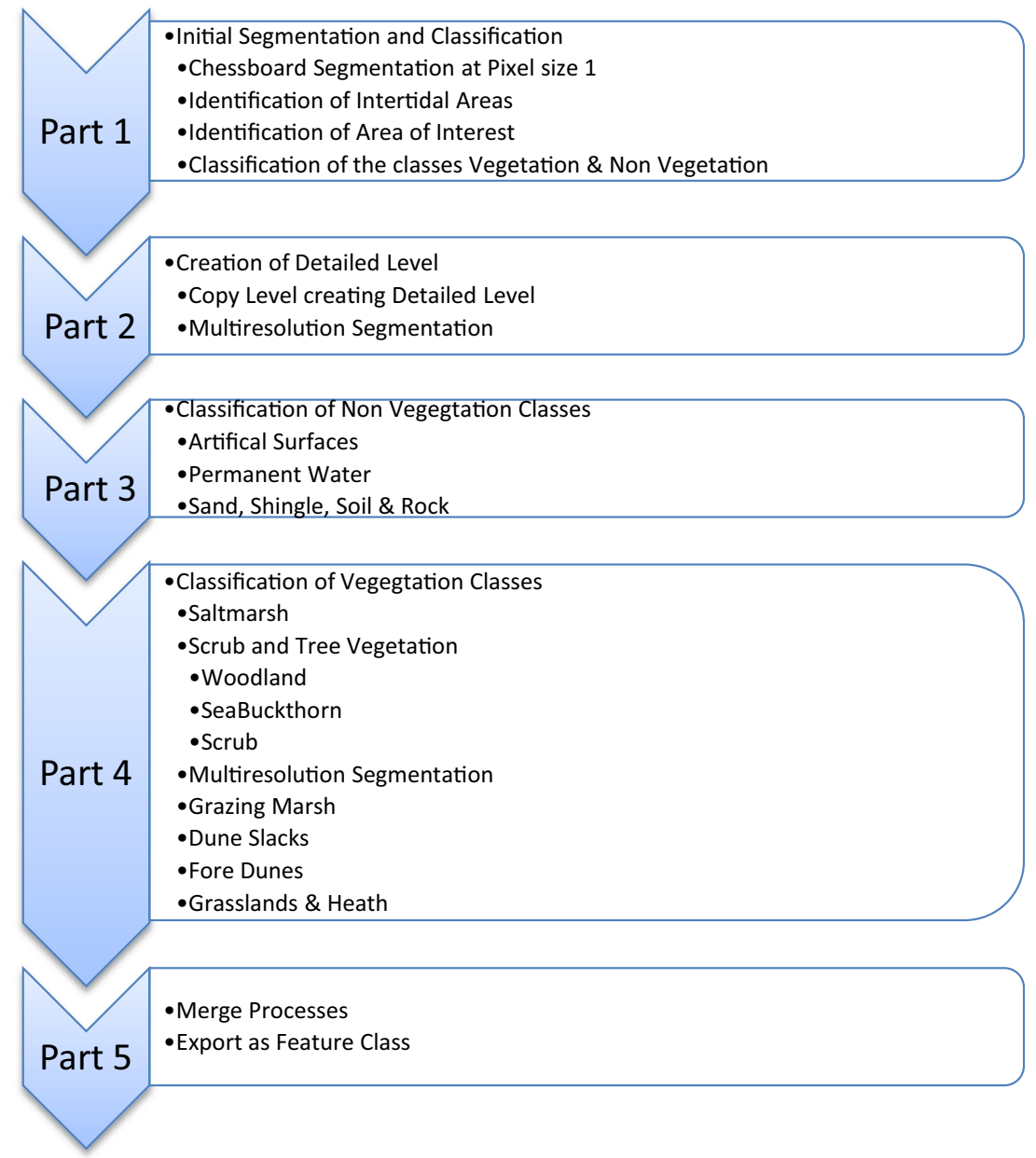


Highest Astronomical Tide (HAT) height being the upper limit of the intertidal area. A second classification is then undertaken to classify all objects into either a Vegetation or Non Vegetation class (Fig. 4 - Centre Image). These results are then merged creating large objects for each class. This allows the subsequent processes to focus on the relevant site areas to identify a habitat. For example, Saltmarsh is only mapped within areas already found to be intertidal and vegetation.

The main stage of the classification is to classify the detailed habitat classes (Fig. 3 - Parts 3 \& 4). This is started by creating the Detailed Habitat Level through a multi-resolution segmentation algorithm (Fig. 3 - Part 2) to create a new lower level in the classification onto which the main classification happens (Fig. 4 - Right Image). Segmentation into these objects has been found to help in classifications, as it allows plant communities to be mapped rather than individual plants when using a pixel based method (Blaschke 2010; Lucas et al. 2011). The software does this segmentation to a lower level so that it can create smaller more detailed objects than those above it and allow for the distinct habitat communities to become objects.

Non vegetation classes are initially classified (Fig. 3 - Part 3); these include Artificial Surfaces, Bare Sand and Water. Thematic data and spectral features are used in the decision rules for non-vegetation classes. This thematic data includes Ordnance Survey VectorMap ${ }^{\mathrm{TM}}$ District data for Buildings, Roads and Railways. The functionality within eCognition to interrogate information from the objects are called Features. These features include simple features like mean spectral values for an object, and advanced features like indices such as Normalized Difference Vegetation Index (NDVI), object extent /shape information and relational information such as border to /distance to. The ability to integrate relational information into the classification is another advantage of using OBIA (Blaschke 2010). These non-vegetation classes are classified before the detailed vegetative classes, as relational rules are used in some of the vegetative classes such as Embryo Dunes; which has a rule based on distance to Bare Sand.

Major vegetation classes are classified in sections, allowing ecological knowledge to help guide and limit the classification. The order of vegetation classes classified is shown in Fig. 3 Part 4. The first to be classified are the scrub and tree classes, this is to remove these objects from potential misclassification as low vegetation types i.e. Dune Slacks - Creeping Willow. Scrub and Tree classes rely on the CHM to distinguish them clearly from other vegetation, as previous studies have found that improvements can be achieved from combining LIDAR and spectral information (Jeong et al. 2016 \& Mucher et al. 2015). In this mapping Scrub is mostly defined as $0.5 \mathrm{~m}$ to $2 \mathrm{~m}$ in height, then Broadleaved Dune Woodlands and Coniferous Dune Woodlands defined as having a height above $2 \mathrm{~m}$ and an area over $2000 \mathrm{~m}^{2}$. While all the classes rely on spectral information in their rules, these early distinctions allow for a greater focus in the remaining classes to be on the wealth of information in the CASI data. Spectral bands used in the rules and appropriate thresholds were decided upon using the various spectral information displays that eCognition has, including the graphical display of the Spectral Selection Information. This shows a histogram of the spectral responses for each band, and can compare them to another class. This also provides the range each class values are within and the amount of overlap between the two classes. To produce an accurate classification is an iterative process, identifying areas of misclassification and adapting rules and thresholds to limit these. This iterative process has been slower on some of the more recent large sites and eCognition Server 9.0 was acquired. This splits the project into tiles $1500 \times 1500$ pixels, and processes each tile individually before stitching the results together. This process is more efficient due to the ability to faster process multiple small tiles rather than a single large scene.

The habitat map is then tidied through a number of merge algorithms, used to combine neighbouring objects of the same
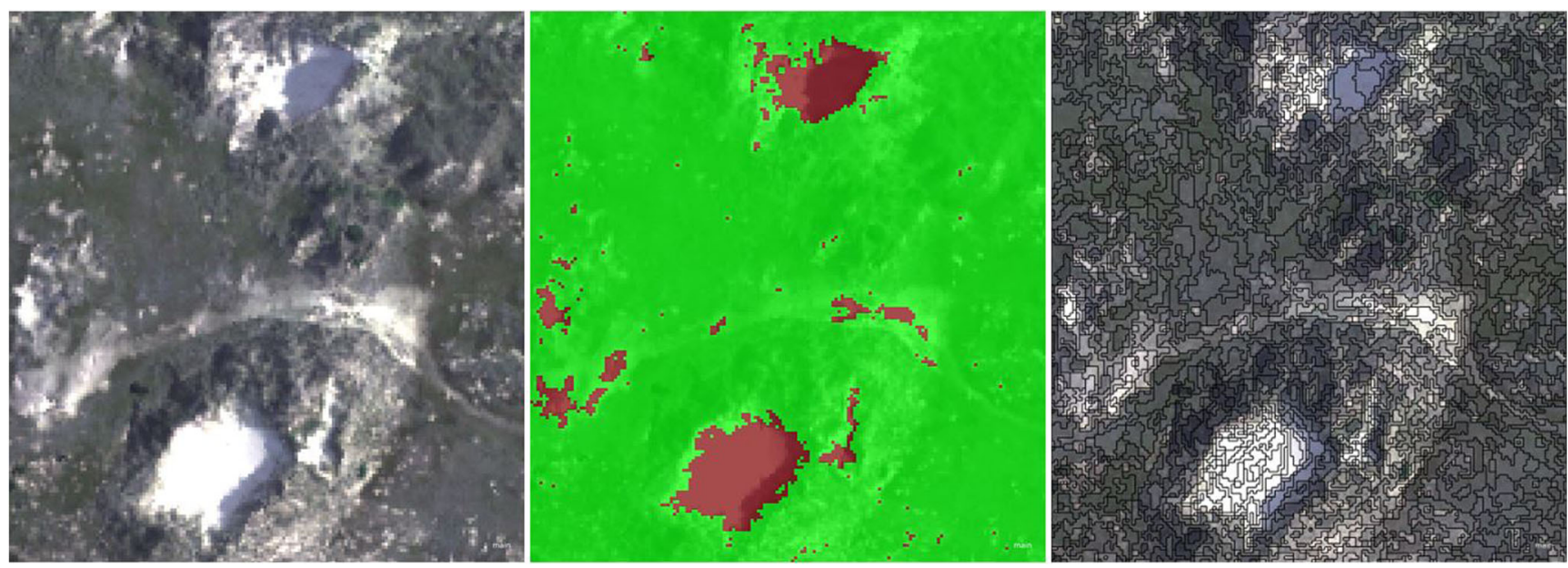

Fig. 4 Left: true colour CASI. Centre: Classification at a pixel level of Vegetation (Green) and Non Vegetation (Brown). Right: Multi-resolution Segmentation carried out on the vegetation and Non Vegetation classification 
class into single larger objects and finally export as a vector dataset (Fig. 3-Part 5). Stage 4 (Fig. 2) of the habitat mapping workflow then carries out QC. This involves three checks, ensuring data matches on tile boundaries, identifying any objects which have not been mapped and checking the results against the training ground data. Once this QC has been undertaken manual edits are made to the classification (Fig. 2 Stage 5). This work did not set out to create a classification purely in one software package or solely as an automated classification but rather to create a high quality and accurate habitat map. This need for high quality and accurate results has allowed us to be confident and open in the fact that we do carry out manual changes. These edits are normally limited to small distinct features falsely classified in larger classes or cleaning of feature edges where a transitional area has been better defined during the ground data collection.

Finalising the habitat map involves a final stage of QC (Fig. 2 - Stage 6), including verification of the results by habitat specialists/ site officers and where possible accuracy assessment. The verification by ecological specialists/ site officers is viewed as crucial in ensuring the results are correct and fit for purpose. This verification takes place through a systematic viewing process, heading through the complete site. The habitat map is compared against the CASI data and Aerial Photography throughout this viewing process. An accuracy assessment is also carried out where sufficient ground data has been collected to train the classification and provide an appropriate number of samples to undertake a robust accuracy assessment. Where sufficient ground data was available for training and accuracy, a subset of the ground data was selected before the classification started and kept separate to the data used for training the classification. An accuracy assessment is then run using eCognition. The ground data is loaded and used to create a Training and Test Area (TTA) mask, which allows the samples to be used on other scene levels. The TTA Mask is then used to test the results and produce an Error Matrix including individual class user and producer accuracy values and an overall accuracy value.

\section{Evolving to operational use}

The mapping work has evolved since 2012 into an operational product, the methodology and process for which has been used every year since development. Lessons learned from class classification (Table 3 shows the habitat map classes and equivalent Annex I habitats) and processing have been fed back into continual improvement over the period of the project (J. Brownett, Ground truthing \& class codes report \& guidance, Unpublished). Additional classes were added due to mapping new sites in 2014 which contained Coastal and Floodplain Grazing Marsh and Shingle - Vegetated.

Each CASI flight generates a unique set of data as the spectral information from the CASI. The spectral signatures of the vegetation vary for various reasons: lighting conditions, differing species making up the vegetation communities and phenological differences (even over the summer capture period). This means that the classification process needs to be adjusted for each site and session of data collection, with a number of changes needed.

The first change when starting the site mapping is to ensure each class needed for the site is enabled within the classification process. This is done by checking which classes had samples collected during ground data collection and ensuring these are the only ones enabled. Doing this stops classes being wrongly identified on the site when they do not exist there, and by checking it with the ground data means there is definitely ground data available to use to adjust spectral rules. The classification also makes use of tide heights, including the HAT. These levels need to be updated to the relevant tide height levels occurring at the site.

Finally the spectral rule thresholds within each class will need adjusting, however the spectral bands used for rules should not be adjusted between sites. This limits variability between sites classified due to the process, while allowing for the different spectral signatures to be accounted for. These spectral rule thresholds may need refining and so an iterative classification process is gone through to do this. Only when the original spectral bands used in the rules do not allow for accurate discrimination of that class should the spectral bands be changed. This has not occurred often and is mostly due to some sites having heavily mown, dry improved grassland compared to more productive growth on other sites or heavy senescence in bracken. By using this classification process and making these changes at each site, we are able to operationally use and repeat sand dune classifications, in an approach we describe as a Semi-Automated Classification.

\section{Results}

The habitat maps produced for each site are available in a Shapefile format under an Open Government License from Data.Gov.uk (Defra 2016). Three examples are shown for North Walney (Fig. 5), Sandwich Dunes (Fig. 6) and Holkham Dunes (Fig. 7).

The maps and associated data have been used to inform Natural England's and other land owners (including conservation bodies) work on the sand dune sites mapped to date; providing a framework for more detailed vegetation mapping and monitoring, informing management plans and monitoring programmes to improve the condition and conservation of these habitats.

The North West Cumbrian Coast (i.e. Seascale \& Drigg Coast, Eskmeals, Haverigg Haws, Sandscale and North Walney) was mapped in 2013; the maps and data have been used to inform management of the sites and various projects. 


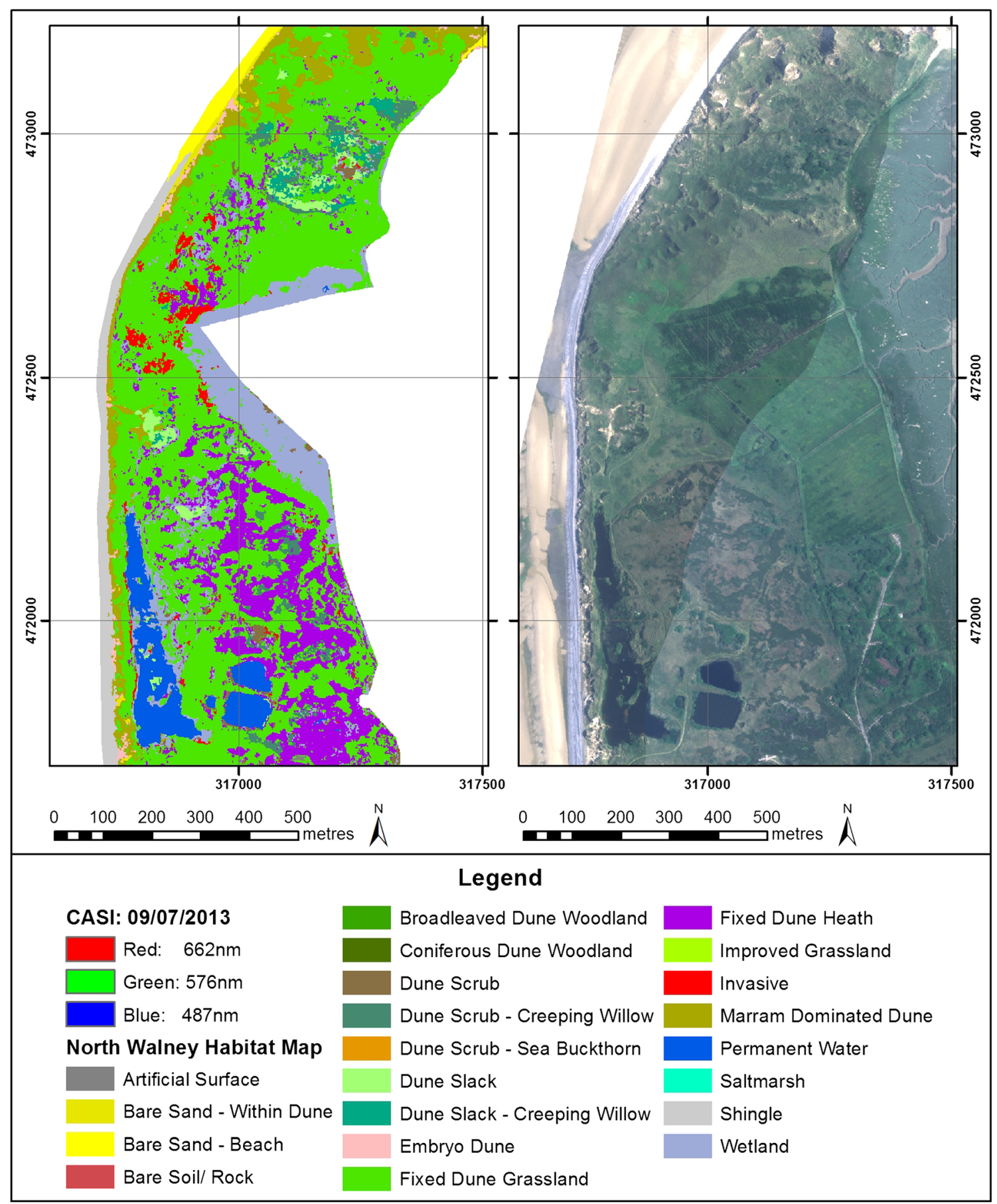

Fig. 5 Habitat map of North Walney, Cumbria (Left) and the CASI data (Right) used in mapping captured in July 2013

The North Walney habitat map (Fig. 5) and habitat extents and proportion table (Table 4) have been used in the 'Dunes of Barrow Project' (Morecambe Bay Partnership 2016) to help target management on the dunes; notably scrub control, removal of invasive species and was used to justify the need for additional bare sand in the dune system. Other identified values and uses of the data have been in providing a complete overview and baseline dataset for whole sites, which can be used where other data does not exist. Examples of where sand dune habitats are rapidly changing through accretion and/or erosion are at Haverigg Haws where the site is rapidly accreting forming new shingle and dunes; Drigg Dunes where cattle grazing has recently been introduced; and Sandscale where the data has been used with historical air photographs to map the declining area of bare sand in the dune system, supporting a move to remobilise areas of dune (Nicola Evans, Natural England Lead Adviser 2016, Personal Communication). 


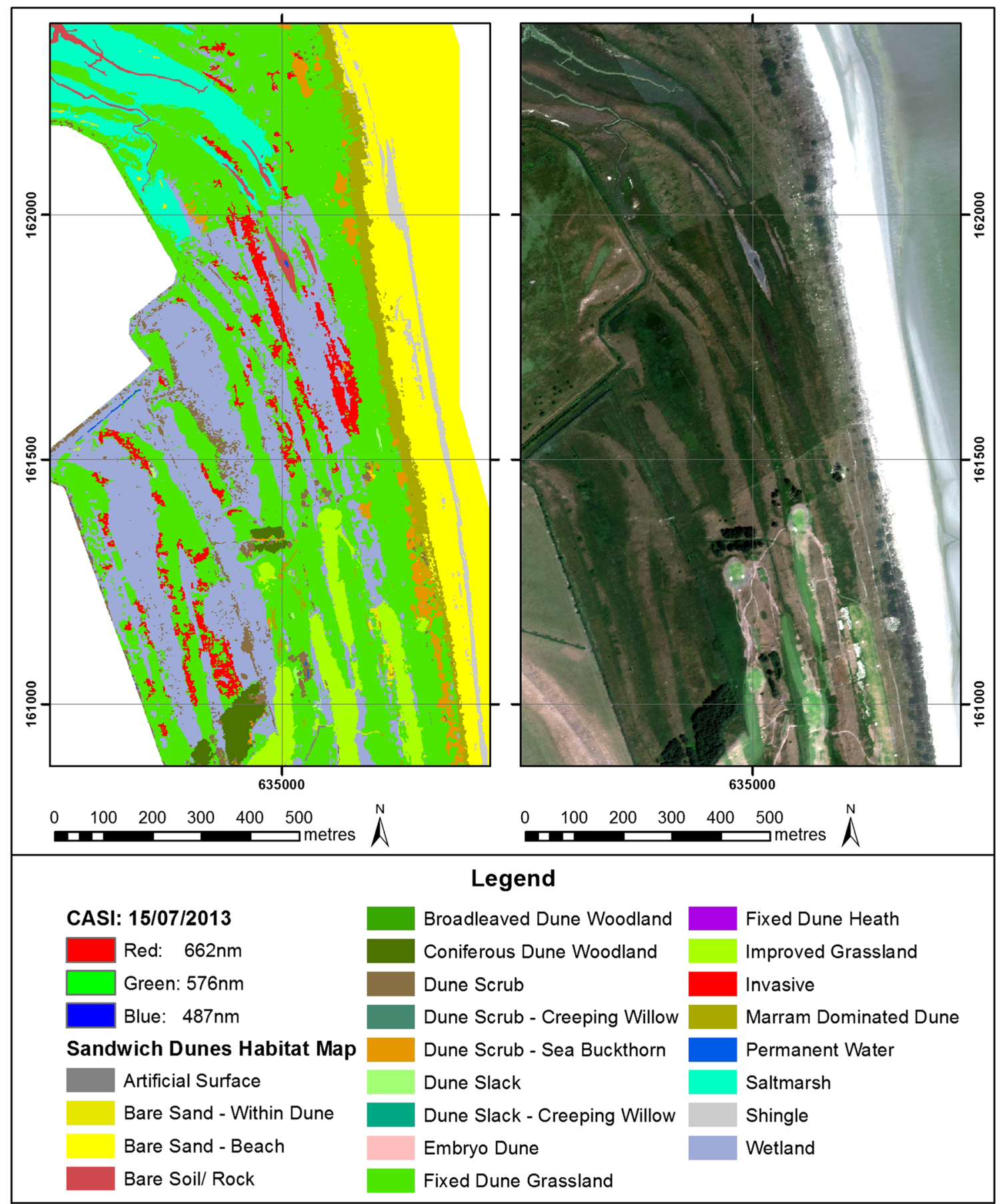

Fig. 6 Habitat map of the North section of sandwich Dunes, Kent (Left) and the CASI data (Right) used for the mapping, captured in July 2013

More widely the data has been used to inform the Marine Conservation Advice Packages (Natural England 2016) for Marine Protected areas that are being developed for the coastal sites (Defra 2012) and will inform future national management and restoration projects.

North Walney (Fig. 5) is dominated by Fixed Dune Grassland with the foredunes being Marram Dominated Dune and small patches of Embryo Dune on the lower slopes. The CASI images also shows steep dune ridges in the North, which are predominantly Marram Dominated Dune, with small areas of Bare Sand - Within Dune. For every site a statistics table is produced showing habitat extents and the proportion of the site covered by a particular habitat (Table 4). The South East section of the map shows large areas of Fixed Dune Heath, which are visible in the CASI image (Fig. 5), and cover $9.14 \%$ of the site (Table 4 ).

The map in Fig. 6 shows the Northern section of Sandwich Dunes. The majority of Sandwich Dunes SSSI is made up of 


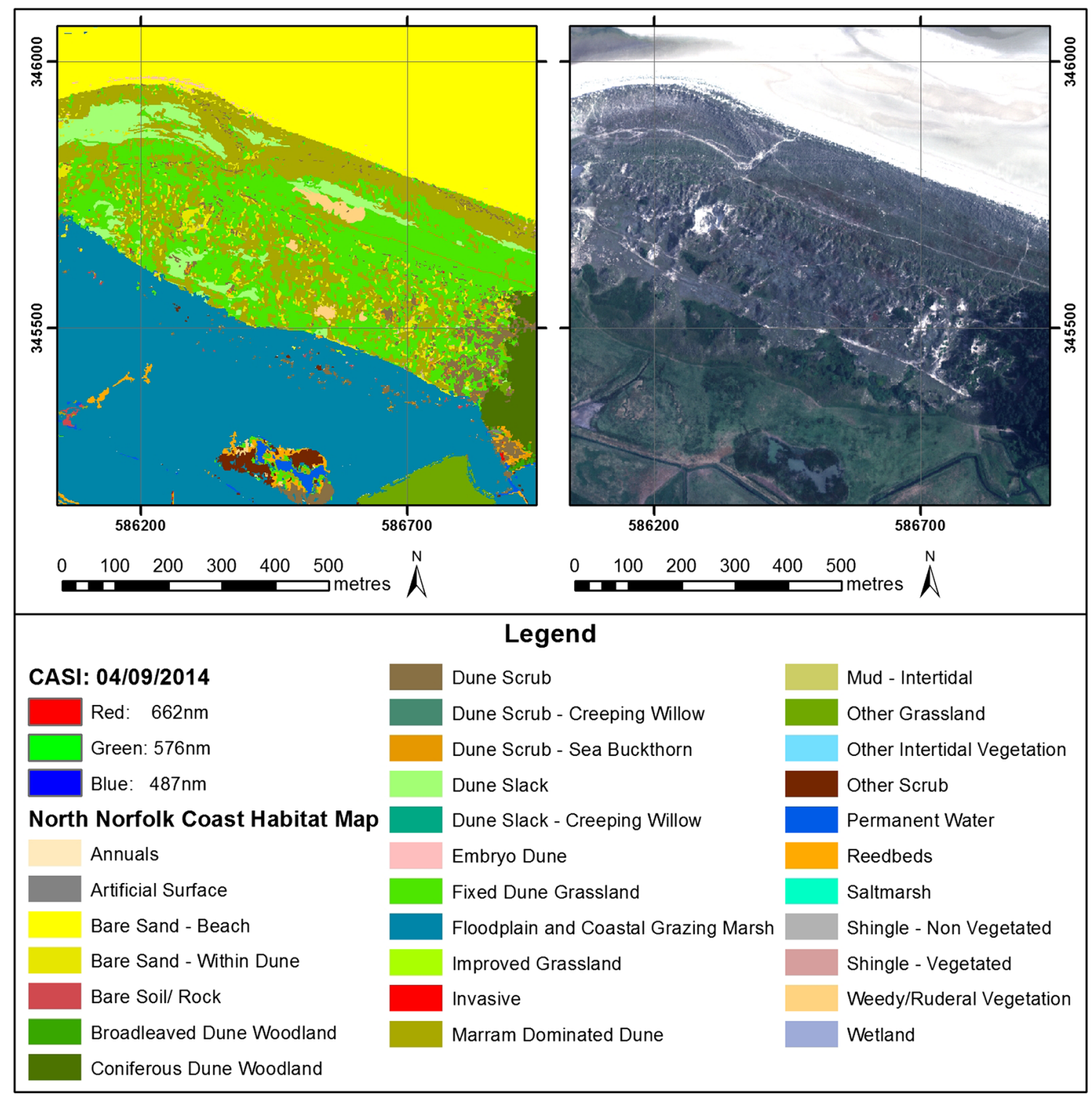

Fig. 7 This habitat map is of Holkham Dune on the North Norfolk Coast, Norfolk

3 golf courses. The southern sections of Fig. 6 show one of these links golf courses, with a noticeable difference in the brightness of the vegetation in the CASI image along the fence line between the golf course and more natural Fixed Dune Grasslands to the north. These Fixed Dune Grasslands have a transition into Wetlands and Saltmarsh as the fingers of dune ridge lessen. The foredune of the site is Marram Dominated Dune in the southern section of the map, with Dune Scrub - Sea Buckthorn behind. The Dune Scrub Sea Buckthorn then becomes the dominant vegetation on the foredune further north.

Figure 7 shows a $1 \mathrm{~km}$ stretch of the $40 \mathrm{~km}$ long North Norfolk Coast mapped. The east section of Fig. 7 are covered by coniferous plantation, but with dune topography underneath and so are classified as Coniferous Dune Woodland. They are fronted by Marram Dominated Dunes and some
Embryo Dunes. There are also large areas of Marram Dominated Dunes within the dune system, maintained by the many areas of Bare Sand - Within Dune visible in the CASI image as white areas.

The final habitat map is always checked by habitat specialists within Natural England. However due to site size, time and cost constraints, it has been difficult to collect enough ground data on most sites to be able to carry out a robust accuracy assessment. However, a priority was made of the North Norfolk Coast site and resource was provided to collect a larger number of samples $(\sim 400+)$ enabling an error matrix accuracy assessment to be undertaken. The sample size was sufficient for all but one class (Invasive) and a robust Error Matrix was created. The overall accuracy for this classification was 0.84 . This figure needs to be considered alongside the individual class accuracies, where there were accuracies 
Table 4 Habitat extents and proportion table for North Walney, Cumbria

\begin{tabular}{lll}
\hline Class & Area $(\mathrm{m} 2)$ & $\begin{array}{l}\text { Proportion }(\%) \\
\text { of the site }\end{array}$ \\
\hline Artificial surface & 11297.14 & 0.84 \\
Bare sand - beach & 30483.96 & 2.26 \\
Bare sand - within Dune & 12041.51 & 0.89 \\
Shingle & 101005.13 & 7.48 \\
Soil or rock & 0.00 & 0.00 \\
Permanent water & 40334.14 & 2.99 \\
Embryo Dune & 17662.50 & 1.31 \\
Marram dominated Dune & 114074.95 & 8.45 \\
Fixed Dune grassland & 629268.49 & 46.62 \\
Fixed Dune heath & 123295.85 & 9.14 \\
Dune slack & 13688.13 & 1.01 \\
Dune slack - creeping willow & 50863.53 & 3.77 \\
Dune scrub & 26763.04 & 1.98 \\
Dune scrub - sea buckthorn & 0.00 & 0.00 \\
Dune Scrub - creeping willow & 50863.53 & 3.77 \\
Broadleaved Dune woodland & 0.00 & 0.00 \\
Coniferous Dune woodland & 0.00 & 0.00 \\
Invasive & 33672.77 & 2.49 \\
Weedy ruderal vegetation & 0.00 & 0.00 \\
Wetland & 90342.55 & 6.69 \\
Improved grassland & 4043.96 & 0.30 \\
Saltmarsh & 0.00 & 0.00 \\
Total & 1349701.17 & 100.00 \\
\hline & & \\
& & \\
\hline
\end{tabular}

ranging between 0.6 and 1 . Only 1 class did not fall within this range and this was for Bare Sand - Within Dune with an accuracy of 0.41 . The other class scores ranged comfortably between these values. Dune Scrub achieved an accuracy of 0.81, Embryo Dune - 0.99, Fixed Dune Grassland - 0.7, Marram Dominated Dune - 0.74 and Coniferous Dune Woodland achieved an accuracy of 1 .

\section{Discussion}

This project aimed to test whether remote sensing can be used, alongside ground truthing, to monitor sand dune habitats and devise a repeatable and credible view of habitat extent. The initial three sites mapped (Winterton Dunes, Norfolk; Studland Dunes, Dorset; \& Saltfleetby-Theddlethorpe Dunes, Lincolnshire) covered the majority of SAC sand dune habitats in England and allowed for a good initial process and ruleset to be developed for use on other sites. It also allowed a better understanding of how this work could be run operationally and the changes in analysis needed between sites.

After the first sites were mapped, a review was undertaken of the ground data and classes; all classes were reviewed, with adjustments recommended for a number of them. The main driver of the review was to create an operationally useful set of class definitions. This has allowed for a better understanding of the classes and reduced some of the ambiguity between the classes. This is important because these definitions help to set the threshold in the class rules, so the ground data samples need to be consistently collected on all sites. As shown by Hearn et al. (2011) there can be large variation between surveyors' assessments of habitats when using the National Vegetation Classification, the effect of this on the classification was considered due its potential to affect the outputs. Clarification was provided for the 'woodland' classes. This involved the use of height and area rules, the height is easily determinable from LIDAR data and shown by Dalponte et al. (2012) to help improve classification accuracy. The use of an area rule allowed individual or clumps or trees to be separated from Woodlands, with these then considered Dune Scrub. Definitions were also changed to minimise the use of percentage cover rules, such as Embryo Dune being defined as greater than $50 \%$ of Elytrigia juncea (sand couch) and/or Leymus arenarius (Lyme Grass). Limiting these is important as it was difficult to match what was seen in the field with the objects created during analysis. This is due to the difficulty in creating objects during segmentation that combine such different habitats (i.e. vegetation and sand), that you would normally try to separate to achieve a good segmentation. This limited the collection of samples with mixed classes, i.e. samples with both embryo dune and bare sand. This reduced the chance of misclassification due to mixed spectral signatures in the sample. However as this is a key feature to the habitat, the OBIA approach still allows the Embryo Dune class to be defined by taking into account bare sand by checking whether it is present in surrounding objects.

The review of the initial habitat mapping highlighted the importance of collecting ground data within 1-2 months of CASI data being collected. This helps to minimise ground data error which can often occur due to the dynamic nature of the sites with vegetation and topographic change, as occurred on Studland Dunes due to the large time between CASI capture and Ground Data collection (Table 2). This also helps minimise site changes caused by major management tasks (like large scale clearance or burning of vegetation).

This work has enabled 11 sites to be mapped and a further 4 sites are in progress, including Sefton Coast and Braunton Burrows. The method described here for the habitat mapping provides an operational tool that has real practical applications. It allows for differences in reflectance and phenological conditions and uses the knowledge and understanding of both the site surveyors and the analyst to guide the classification. Only on rare occasions did the spectral bands used for the rules need to change. In some circumstances, the class rules needed to be modified to allow for atypical or unusual circumstances, for example where an unimproved grassland had been tightly cut and was desiccated; this was being confused with 
the classes called Marram Dominated Dune or Fixed Dune Grassland. The developed process tree approach saved a considerable amount of time on repeated sites. By running the process tree once the classification was set up, it was possible to go through and check each class result which flagged up where modification of rules needed to be made to fit individual site circumstances.

There are limitations to the classification system. It could be argued that the need for an analyst to develop site specific rule thresholds mean that it is not entirely operational. However, given the sensible results that have been achieved over a number of sites this is not an issue. Another limitation to the classification is that it cannot provide an uncertainty value for each object. There are a number of reasons for this including the merging of object together to limit their number for processing. This improved performance especially that of the output vector data, which would be extremely slow and inefficient otherwise for the final checks and changes. Another reason is the multiple classification levels, and some of the relational rules used, meaning the uncertainty value output from eCognition would not always be the true value used when the object was classified.

QC procedures are carried out through the whole process. The final major step of QC happens after the classification is exported from eCognition. The key to this step of QC is that habitat specialists and site officer check that the habitat map matches what is seen on the ground and the local understanding of habitats at a site. This is carried out by staff not involved with running the classification but who have collected the ground data, so do have a good and recent understanding of the site. This provides suitable QC and is the minimum amount we accept for the habitat maps. An ideal situation to be in would be for each individual site to have an error matrix calculated. This would allow for a quantitative confidence of individual classes and the overall accuracy. Unfortunately, because of time constraints, this was not done on the first sites that were classified. On these sites ground data was collected but time limitations meant that insufficient ground data samples were collected to allow both training and accuracy assessments to be made. As further mapping work was carried out we ensured that sufficient samples were taken to allow both training and accuracy assessments to be made. This was because greater experience allowed for better planned, targeted and more rapid data collection. This allowed the project to collect enough ground data on the North Norfolk Coast for independently using some of it to assess accuracy of the classification. It should also allow for future sites; Sefton Coast and Braunton Burrows, to have error matrices calculated.

The overall accuracy of the North Norfolk Habitat Map is 0.84. Mapping will never be $100 \%$ accurate due to inevitable errors with ground data (Foody 2011) and this achieved level of accuracy is comparable to that achieved and accepted for other UK work like the Phase 1 habitat mapping carried out for Wales
(Lucas et al. 2011) and Land Cover Map 2007 (Morton et al. 2011). The current overall accuracy is fit for purpose as backed up by the positive QC that has been received from the habitat specialists. Bare Sand - Within Dune is the one class accuracy that is lower than wanted. There are some potential reasons for this, first being the size of the habitat. Many of the ground data samples for this class are of either dune blow outs or paths and tracks. The misclassification of this habitat is generally on the paths or tracks, which are narrow features. This means that the resolution of the CASI data of $1 \mathrm{~m}$ limits the number of pixels with a pure sand spectral signature and will have stopped the correct classification to Non Vegetation on the initial stage of the classification. The next step is to repeat the accuracy assessment to check the stability of the method. This additional check will also allow for individual class scores to be looked at with greater scrutiny. This should highlight whether there are common classes which have lower accuracy scores or if the lower scores are just down to differences in surveyor interpretation (Hearn et al. 2011) and the problems of imperfect ground data (Foody 2011). Any classes that show lower accuracy scores can then be reviewed and may need further refinement.

The habitat maps have been a valuable resource to site officers, providing them with baseline habitat maps to guide site management plans. A common issue with sand dune systems is that they are stabilised and need re-mobilisation (Provoost et al. 2011). This challenge exists at North Walney and the habitat extents backed up an assessment of the areas of bare sand, which provided justification for creation of new areas of bare sand. The habitat map can now help in planning the locations for bare sand creation alongside targeting the management to control invasive and scrub species.

\section{Conclusion}

A key requirement for Natural England is to be able to map and monitor change in habitat location and extent. This is important in setting conservation and management objectives and assessing site condition on coastal sand dune habitat SACs and SSSIs. The project has been successful in developing an innovative method of habitat mapping, which has been adapted to a range of sand dune habitat sites around England. This is producing maps and extent information of the sand dune habitats for site managers. The habitat maps are helping to update our knowledge and understanding of dunes since the last national Sand Dune Survey of England in the 1990's (Radley 1994).

Remote sensing techniques can provide mapping over large sites; which would otherwise be impossible to capture in a ground based study alone even where an element of remote sensing (e.g. aerial photography) has been used. A true picture of a site can only be achieved through the collaboration between the disciplines of remote sensing and ecology with local site knowledge. The collaboration between Natural 
England and the Environment Agency has allowed this relationship to successfully develop. Validation of remote sensing outputs is necessary to ensure the results are correct and enable them to be used with any errors clearly understood. Using the qualitative and quantitative QC procedures discussed this habitat mapping has shown to be successful.

There are many opportunities for the use of the outputs of this project, and a potential to further develop this area of work for operational mapping of other habitat types for both Natural England and Environment Agency. The project will continue to map the remaining SAC sand dune habitats in England, and look to use these habitat maps as baselines in future remotely sensed habitat monitoring projects. They can also aid in understanding how topographical changes, such as those measured in North Norfolk using LIDAR data (Brownett et al. 2015) have or could affect the dune habitats.

The tools developed as part of this project will prosvide evidence to meet and deliver the conservation objectives for sand dunes and better understand their structure as a natural flood defence for both Natural England and Environment Agency.

Open Access This article is distributed under the terms of the Creative Commons Attribution 4.0 International License (http:// creativecommons.org/licenses/by/4.0/), which permits unrestricted use, distribution, and reproduction in any medium, provided you give appropriate credit to the original author(s) and the source, provide a link to the Creative Commons license, and indicate if changes were made.

\section{References}

Blaschke T (2010) Object based image analysis for remote sensing. ISPRS J Photogramm Remote Sens 65:2-16

Brown K, Hambidge C, Matthews A (2003) The development of remote sensing techniques for marine SAC monitoring http://publications. naturalengland.org.uk/publication/62029? category $=61003$. Accessed 18 Feb 2015

Brownett J, Mills R, Rees S (2015) The use of remote sensing to assess elevation change on the North Norfolk coast before and after the December 2013 storm surge. Sand Dune and Shingle Network Newsletter 21:4

Corbane C, Lang S, Pipkins K, Alleaume S, Deshayes M, Millan V, Strasser T, Borre J, Toon S, Michael F (2015) Remote sensing for mapping natural habitats and their conservation status - new opportunities and challenges. Int J Appl Earth Obs Geoinf 37:7-16

Dalponte M, Bruzzone L, Gianelle D (2012) Tree species classification in the southern alps based on the fusion of very high geometrical resolution multispectral/hyperspectral images and LIDAR data. Remote Sens Environ 123:258-270

Defra (2012) Report of the Habitats \& Wild Birds Directive Implementation Review. https://www.gov. uk/government/uploads/system/uploads/attachment_data/file/69513 /pb13724-habitats-review-report.pdf. Accessed 8th February

Defra (2016) CASI and LIDAR Habitat Map. https://data.gov. uk/dataset/casi-and-lidar-habitat-map. Accessed 15 Nov 2015

Natural England (2016) Marine protected areas: conservation advice packages https://www.gov.uk/government/collections/conservationadvice-packages-for-marine-protected-areas. Accessed 8 Feb 2016

Foody GM (2011) Assessing the accuracy of land cover change with imperfect ground reference data. Remote Sens Environ 114:2271-2285
Hearn S, Healey J, McDonald M, Turner A, Wong J, Stewart G (2011) The repeatability of vegetation classification and mapping. J Environ Manag 92:1174-1184

Hussain M, Chen D, Cheng A, Wei H, Standley D (2013) Change detection from remotely sensed images: from pixel-based to object-based approaches. ISPRS J Photogramm Remote Sens 80:91-106

Jeong S, Mo Y, Kim H, Park C, Lee D (2016) Mapping riparian habitat using a combination of remote-sensing techniques. Int J Remote Sens 37:1069-1088

JNCC (2013) Habitat conservation status reports - 3rd UK habitats directive reporting $2013 \mathrm{http}: / / j n c c . d e f r a . g o v . u k /$ page-6563. Accessed: 8 Feb 2016

JNCC (2015) UK BAP priority habitats http://jncc.defra.gov.uk/page5718. Accessed 9 Nov 2015

JNCC (2016) Annex I habitats and Annex II species occurring in the UK http://jncc.defra.gov.uk/page-1523. Accessed 8 Feb 2016

Lucas R, Rowlands A, Brown A, Keyworth S, Bunting P (2007) Rulebased classification of multi-temporal satellite imagery for habitat and agricultural land cover mapping. ISPRS J Photogramm Remote Sens 62:165-185

Lucas R, Medcalfe K, Brown A, Bunting P, Breyer J, Clewley D, Keyworth S, Blackmore P (2011) Updating the phase 1 habitat map of Wales, UK, using satellite sensor data. ISPRS J Photogramm Remote Sens 66:81-102

Medcalf KA, Parker JA, Turton N, Finch C (2011) Making earth observation work for UK biodiversity conservation - Phase 1. JNCC Report No. 495 Phase 1, JNCC Peterborough 2014

Medcalf KA, Parker JA, Turton N, Bell G (2013) Making earth observation work for UK biodiversity conservation - Phase 2. JNCC Report 495 Phase 2, JNCC Peterborough 2014

Morecambe Bay Partnership (2016) Dunes of Barrow Project http://www.morecambebay.org.uk/news/barrow-dunes. Accessed 22 Aug 2016

Morton D, Rowland C, Wood C, Meek L, Marston C, Smith G, Wadsworth R, Simpson IC (2011) Final report for LCM2007 - the new UK land cover map. Centre for ecology \& hydrology. $\mathrm{http}: / /$ auth-ceh.axis 12.com/sites/default/files/LCM2007\%20 Final\%20Report.pdf. Accessed 24 Mar 2015

Mucher C, Roupioz L, Kramer H, Bogers M, Jongman R, Lucas R, Kosmidiou V, Petrou Z, Manakos I, Padoa-Schioppa E, Adamo M, Blonda P (2015) Synergy of airborne LIDAR and worldview-2 satellite imagery for land cover and habitat mapping: a BIO SOSEODHaM case study for the Netherlands. Int J Appl Earth Obs Geoinf 37:48-55

Natural England (2016) Marine Conservation Advice: project summary

Petchey S, Brown K, Hambidge C, Porter K, Rees S (2011), Natural England/environment agency collaboration: operational use of remote Sensing for environmental monitoring http://publications. naturalengland.org.uk/publication/130046. Accessed 18 Feb 2015

Provoost S, Jones MLM, Edmondson SE (2011) Change in landscape and vegetation of coastal dunes in Northwest Europe: a review. J Coast Conserv 15:207-226

Pye K, Saye S, Blott S (2007) Sand dune processes and management for flood and coastal defence. Part 1: Project overview and recommendations. Department for Environment, Food and Rural Affairs. http://sciencesearch.defra.gov.uk/Document.aspx? Document= FD1302_5395_TRP.pdf. Accessed 19 Feb 2015

Radley GP (1994) Sand dune vegetation survey of great Britain: a national inventory: part 1: England, JNCC Peterborough

Strasser T, Lang S (2015) Object-based class modelling for multi-scale riparian forest habitat mapping. Int J Appl Earth Obs Geoinf 37:29 37

Toth C, Jozkow G (2016) Remote sensing platforms and sensors: a survey. ISPRS J Photogramm Remote Sens 115:22-36 